\title{
Conservative treatment of delayed cerebral radiation necrosis
}

\author{
PAMELA J SHAW, D BATES \\ From the Department of Neurology, Royal Victoria Infirmary, Newcastle upon Tyne, UK
}

SUMMARY A 63-year-old man developed delayed cerebral radiation necrosis following radiotherapy to a nasopharyngeal carcinoma. Complete resolution of his neurological deficit resulted from corticosteroid therapy alone. Serial CT scans showed the disappearance of the patients' mass lesion. The literature on cerebral necrosis following radiotherapy of extracranial neoplasms is reviewed with particular emphasis on management.

Delayed cerebral necrosis is an infrequent and often unrecognised sequel to therapeutic irradiation of extracranial neoplasms. This complication was first described by Fischer and Holfelder in 1930.' Their patient developed delayed cerebral radiation necrosis seven years after irradiation of a basal cell carcinoma of the scalp. Subsequent case reports have described delayed cerebral radiation necrosis following radiotherapy for tumours of the scalp, ${ }^{2-27}$ paranasal sinuses, ${ }^{18-23}$ nasopharynx, ${ }^{2124-25}$ middle ear, ${ }^{26}$ parotid gland, ${ }^{21} 27$ and lacrimal gland. ${ }^{21} 28$ The latency between the end of irradiation and the onset of clinical symptoms has varied from three months to 19 years. $^{\text {? }}$

In a previously normal brain delayed cerebral radiation necrosis usually manifests itself as a space occupying lesion, which may be difficult to distinguish from primary or metastatic cerebral tumour or from cerebral inflammatory disease such as abscess, focal encephalitis or vasculitis. Despite recognition of the problem, it continues to occur because: (1) "Safe" radiation thresholds have not been precisely established for cerebral tissue, (2) Individual tolerance of radiation is variable, (3) The threshold for injury may be lowered by concomitant chemotherapy, ${ }^{29-30}$ hypertension, ${ }^{31}$ or systemic illness, (4) Radiation dosage may deliberately exceed

Address for reprint requests: Dr Pamela J Shaw, Department of Neurology, Royal Victoria Infirmary, Queen Victoria Road, Newcastle upon Tyne, NE1 4LP, UK.

Received 24 November 1983 and in revised form 16 May 1984. Accepted 21 May 1984 cerebral tissue tolerance in order to achieve an adequate therapeutic response.

Several authors have emphasised that, if left untreated, delayed cerebral radiation necrosis is usually irreversible, progressive, and often fatal. ${ }^{32-33}$ Surgical excision of the necrotic tissue has been widely regarded as the treatment of choice. ${ }^{14} 213334$ Our case illustrates the potential value of primary corticosteroid therapy in delayed cerebral radiation necrosis.

\section{Case report}

A 63-year-old retired Libyan merchant presented in January 1980 with a three-month history of epistaxis. Subsequent investigation showed that he had a non-keratinising squamous carcinoma involving the left side of the postnasal space, with some erosion of the upper clivus and petrous apex. He was treated with radiotherapy, receiving 4270 rads to the tumour, in ten sessions, over 25 days. The two fields used (right lateral face, and left lateral face) were each $10 \times 7 \mathrm{~cm}$ (fig, a and b). He remained well for two years, but then developed progressive bilateral visual failure. Ophthalmological examination revealed the presence of bilateral optic atrophy, and a diagnosis of radiation induced optic neuritis was made.

In May 1982, 28 months following the radiotherapy, he presented with a three-week history of right-sided headache, and progressive left-sided weakness. The positive findings on examination were: upper motor neuron left facial weakness, moderately severe pyramidal weakness of the left arm and leg, left homonymous hemianopia, and left sided sensory inattention. There was bilateral optic atrophy, and visual acuity was reduced to $6 / 36$ on the left and $6 / 60$ on the right. CT scan showed an extensive low density lesion in the right temporo-parietal area, with marked shift 
(a)
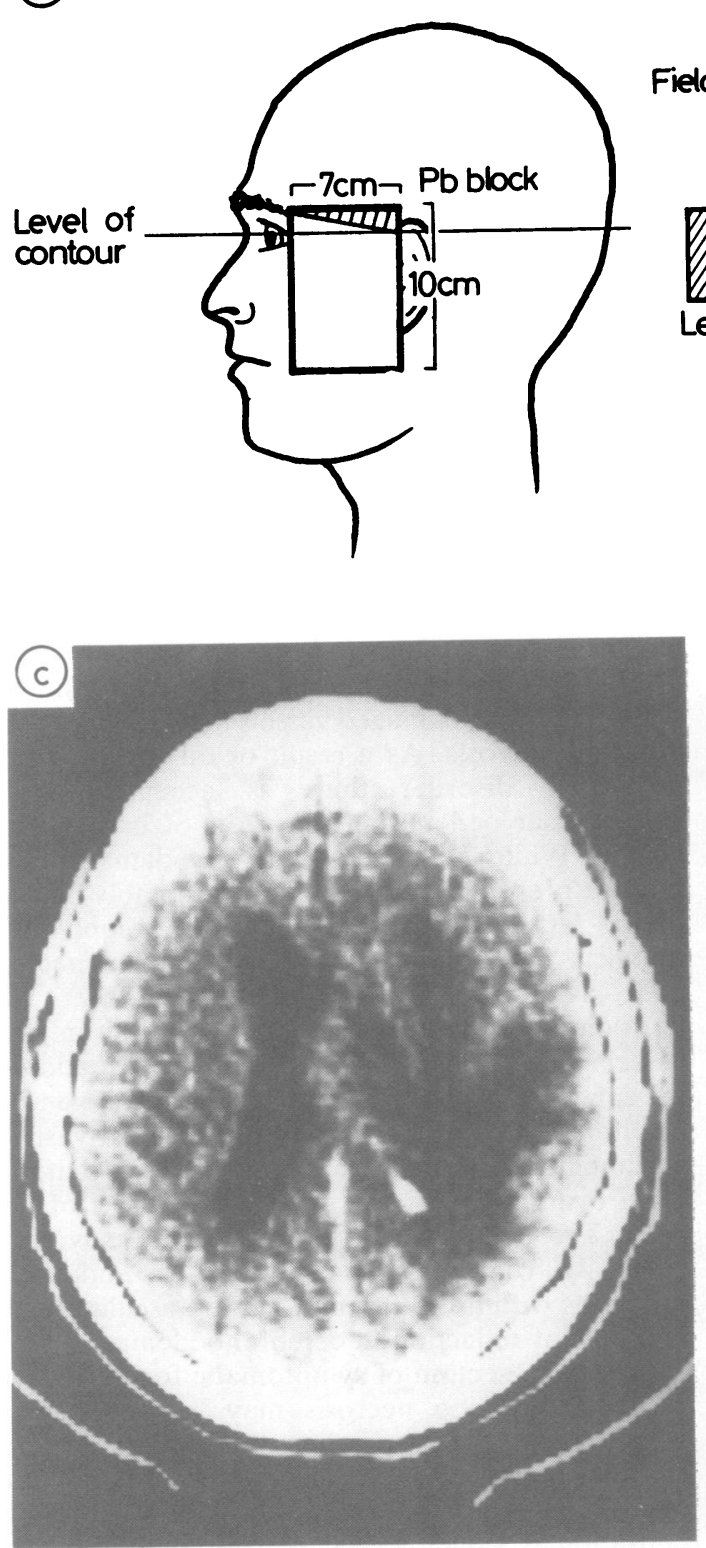
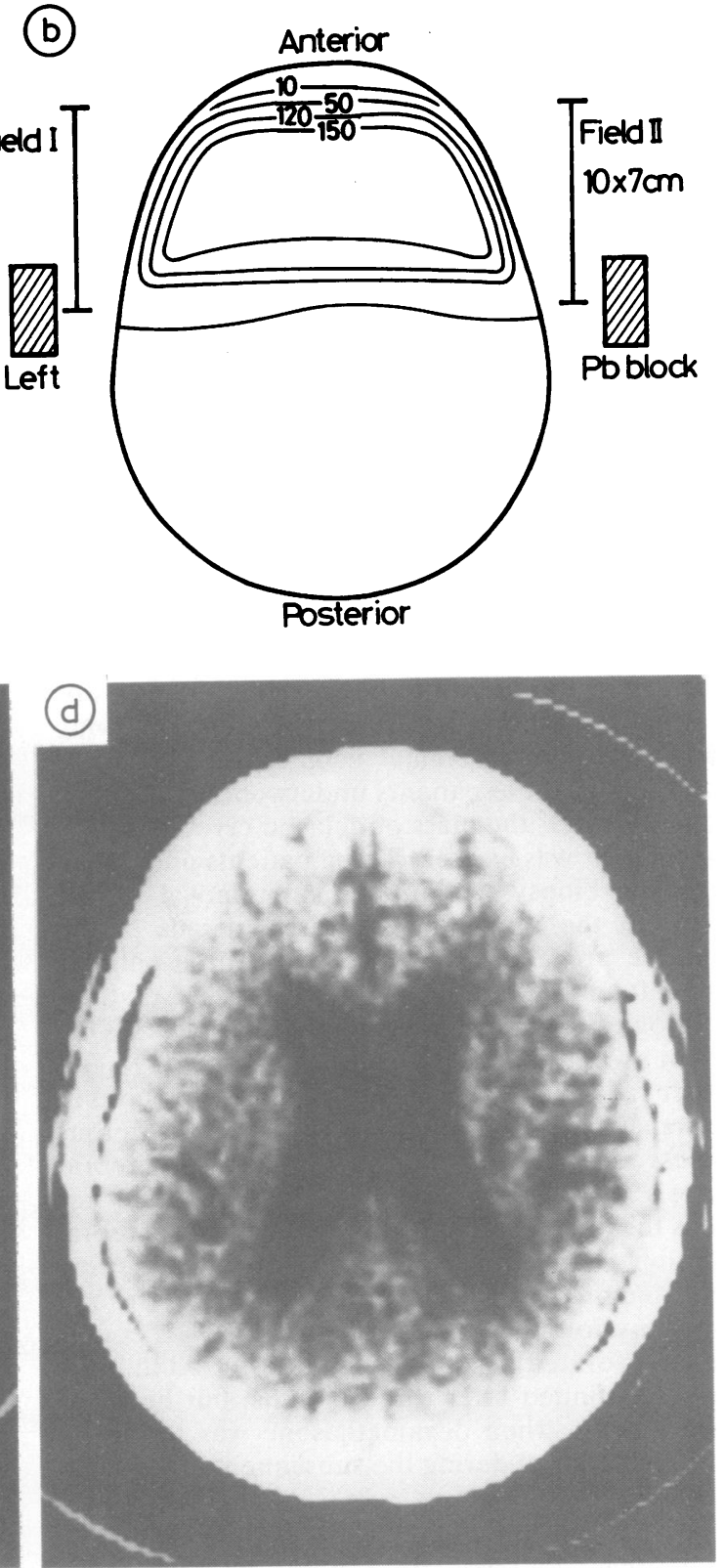

Figure (a) Diagram of radiation treatment portal (Field 1), (b) Isodose radiation curves, (c) CT scan showing an extensive area of low density with mass effect, extending beyond the treated volume, in the right temporo-parietal region, (d) CT scan showing a moderate degree of cerebral atrophy and resolution of the previously demonstrated low density mass. 
of the ventricular system to the left, and little enhancement with contrast (fig, c). Right carotid angiography showed a normal right carotid system, with some shift of the anterior and middle cerebral vessels by an avascular temporoparietal mass. A clinical diagnosis of delayed cerebral radiation necrosis was made. The patient refused operation, and he was therefore treated symptomatically with dexamethasone, in an initial dose of $16 \mathrm{mg}$ daily. He improved dramatically and within two weeks there was complete resolution of his right hemisphere neurological signs. He returned to Libya on a reducing course of dexamethasone, but returned for re-assessment in February 1983. At that time he was taking dexamethasone $1.5 \mathrm{mg}$ twice daily. Detailed neurological examination revealed persistent optic atrophy and impaired visual acuity, but no other abnormal signs. A repeat CT scan showed a moderate degree of cerebral atrophy. The previous noted spaceoccupying lesion was no longer shown (fig, d).

\section{Discussion}

A review of the literature has revealed 39 cases of delayed cerebral necrosis with mass effect, following irradiation of extra-cranial neoplasms. ${ }^{1-25} 272834-36$ Thirty-five of these patients underwent craniotomy, and in 26 cases, the mass of delayed cerebral radiation necrosis was excised. Three patients underwent diagnostic biopsy without radical removal of the lesion. In the remaining six cases, details of the operative procedure are uncertain. Three patients were left untreated and all of them died of their neurological complications, within three years. One patient was managed with chemotherapy and further radiotherapy. Steroid treatment was used in the management of only five cases. ${ }^{12} 13202234$ In four of these, surgical resection of the mass of cerebral necrosis was also undertaken. The case of Eyster $e t a l$ is the first reported instance of delayed cerebral radiation necrosis in which corticosteroid therapy was attempted. ${ }^{20}$ This patient had a right frontal lobectomy followed by dexamethasone. His condition deteriorated abruptly when the steroid therapy was discontinued after three months, but he recovered quickly when dexamethasone was restarted. He remained well during the subsequent three years of follow up. Littmann's case is similar, in that a pre-frontal lobectomy was followed by dexamethasone therapy for three months, with improvement in the patient's condition. ${ }^{13}$ The case of Quieroz and $\mathrm{Da}$ Cruz Neto required massive doses of dexamethasone to control his neurological symptoms, after right temporal lobectomy. ${ }^{12}$ This patient died of gastro-intestinal haemorrhage. Kusske et al reported a patient whose deficit improved following resection of $50 \%$ of the right frontal lobe. ${ }^{22}$ Prior to surgery dexamethasone had alleviated the patient's symptoms. In the case of
Martins et al, biopsy of the lesion was performed, without radical surgical resection. ${ }^{34}$ This patient was maintained on dexamethasone $4 \mathrm{mg}$ per day for six months. He was followed for 30 months and remained well, apart from mild cognitive impairment.

Our case illustrates three important points with regard to the management of delayed cerebral radiation necrosis. Firstly, a working diagnosis of delayed cerebral radiation necrosis can sometimes be made from the clinical picture, together with the CT scan and angiographic findings, without subjecting the patient to cerebral biopsy. Secondly, a large mass of necrosis can resolve without surgery. Thirdly, corticosteroids can have a valuable primary therapeutic role in the treatment of delayed cerebral radiation necrosis.

The pathogenesis of delayed cerebral radiation necrosis remains uncertain, but most workers consider that the first stage is a barrier disorder of small blood vessels, resulting from endothelial injury. There is insudation of plasma proteins into the vessel wall, and the damaged vessels may undergo acute fibrinoid necrosis. As a result of this primary microvascular disorder there is accumulation of extracellular oedema and necrosis of brain parenchyma. White matter is selectively damaged with relative preservation of cortex, presumably because of the latter's more abundant blood supply. Histological examination reveals coagulative necrosis and cavitation of white matter, together with fibrinoid necrosis and thrombus formation in small vessels and resultant luminal occlusion. In addition the small vessels show medial fibrosis and adventitial proliferation and there is frequently perivascular accumulation of homogeneous fibrinoid material. Glial overgrowth occurs in relation to foci of necrosis. The beneficial effects of steroids may result primarily from the restoration of the endothelial junctions within the cerebral micro-vasculature and consequent reduction in cerebral oedema.

Surgical resection of symptomatic foci of delayed cerebral radiation necrosis may be necessary in some cases. However, when the clinical evidence favours a diagnosis of delayed cerebral radiation necrosis and the risk of intra-cranial spatial decompensation is small, a trial of steroid therapy may alleviate the patient's symptoms and make craniotomy unnecessary. Further experience with steroids is required, for a better assessment of their usefulness in this rare condition.

We thank Dr PJDK Dawes, Department of Radiotherapy, for his help and advice in the preparation of this paper. 


\section{References}

' Fischer AW, Holfelder H. Lokales Amyloid im Gehirn. Dtsch Z Chir 1930;227:475-83.

${ }^{2}$ Pennybacker J, Russell DS. Necrosis of the brain due to radiation therapy: clinical and pathological observations. J Neurol Neurosurg Psychiatry 1948;11:18398.

${ }^{3}$ Lowenberg-Scharenberg K, Bassett RC. Amyloid degeneration of the human brain following $x$-ray therapy. J Neuropathol Exp Neurol 1950;9:93-102.

${ }^{4}$ Foltz EL, Holyoke JB, Heyl HL. Brain necrosis following $x$-ray therapy. $J$ Neurosurg $1953 ; 10$ :423-9.

${ }^{5}$ Dugger GS, Stratford JG, Bouchard J. Necrosis of the brain following roentgen irradiation. Am J Roentgenol 1954;72:953-60.

- Boellaard JW, Jacoby W. Röntgenspätschäden des Gehirns. Acta Neurochir (Wien) 1962;10:533-64.

${ }^{7}$ Chandler A, Tucker FC, Herzberger EE. Late radiation necrosis of the brain. Wis Med J 1964;63:297-300.

${ }^{8}$ Marra A, Giuffrè R. Late cerebral radionecrosis. Eur Neurol 1968; 1:234-46.

${ }^{9}$ Mandybur TI, Gore I. Amyloid in late postirradiation necrosis of the brain. Neurology (Minneap) 1969; 19: 983-92.

${ }^{10}$ Cambier J, Escourolle R, Lechevalier B, Delaporte P, Lhuillier M. Radiolésion retardée du cerveau consécutive à l'irradiation d' un épithélioma spino-cellulaire de cuir chevelu par le bêtatron. Rev Neurol (Paris) 1972;126: 179-90.

" Piazza G, Gaist G, Padovani R, Morrone B. Necrosi cerebrale pseudotumorale tardiva secondaria ad irradiazone di epithelioma cuoio capelluto. Pathologica 1974; 66:383-96.

12 Queiroz LDS, Da Cruz Neto JN. Late pseudotumoral brain necrosis following irradiation of a scalp neoplasm. Case report. J Neurosurg 1976;45:581-4.

${ }^{13}$ Littmann $\mathbf{P}$, James $\mathbf{H}$, Zimmerman $\mathbf{R}$, Slater $\mathbf{R}$. Radionecrosis of the brain presenting as a mass lesion: A case report. J Neurol Neurosurg Psychiatry 1977;40:827-9.

14 Matsumura H, Ross ER. Delayed cerebral radionecrosis following treatment of carcinoma of the scalp: Clinicopathologic and ultrastructural study. Surg Neurol 1979; 12: 193-204.

15 Pardo-Mindán FJ, Delgado G, Ezcurdia J, Quintanilla E. Delayed cerebral radionecrosis following treatment of basal cell carcinoma. Arch Neurol 1979;36:382-3.

${ }^{16}$ Van Dellen JR, Danziger A. Failure of computerized tomography to differentiate between radiation necrosis and cerebral tumour. $S$ Afr Med J 1978; 53:171-2.

17 Lampe I. Radiation tolerance of the central nervous system. In: Buschke F, ed. Progress in Radiation Therapy. NY, London, Grune and Stratton. 1958:224-36.

${ }^{18}$ Bernasconi V, Giovanelli M, Perria C, Wildi E. La radionecrosi cerebrale tardiva ad evoluzione pseudo- tumorale. Minerva Neurochir 1967;11:28-41.

${ }_{19}$ Amico G, Canger R. Radionecrosi cerebrale tardiva ad evoluzione ipertensiva endocranica. $G$ Psichiatr Neuropatol 1967;95:533-45.

${ }^{20}$ Eyster EF, Nielson SL, Sheline GE, Wilson CB. Cerebral radiation necrosis simulating a brain tumour. $J$ Neurosurg 1974;39:267-71.

${ }^{21}$ Rottenberg DA, Chernik NL, Deck MDF, Ellis F, Posner JB. Cerebral necrosis following radiotherapy of extracranial neoplasms. Ann Neurol 1977;1:339 57

${ }^{22}$ Kusske JA, Williams JP, Garcia JH, Pribam HW. Radiation necrosis of the brain following radiotherapy of extracerebral neoplasms. Surg Neurol 1976;6:15-20.

${ }^{23}$ Mikhael MA. Radiation necrosis of the brain: Correlation between computed tomography, pathology, and dose distribution. J Comput Assist Tomogr 1978;2:71-80.

${ }^{24}$ Krayenbühl H, Ruttner JR. Röntgenspätschäden des Schläfenhirns nach Hochvoltbestrahlung maligner Tumoren des Epipharynx. Schweiz Med Wochenschr 1973; 103:225-31.

${ }^{25}$ Okeda R, Shibata T. Radiation encephalopathy-An autopsy case and some comments on the pathogenesis of delayed radionecrosis of the central nervous system. Acta Pathol Jpn 1973;23:867-83.

${ }^{26}$ Boden G. Radiation myelitis of the brain-stem. J Fac Radiol 1950;2:79-94.

${ }^{27}$ Diengdoh JV, Booth AE. Postirradiation necrosis of the temporal lobe presenting as a glioma. J Neurosurg 1976;44:732-4.

28 Takeuchi J, Hanakita J, Mitsuyuki A, Handa H. Brain necrosis after repeated radiotherapy. Surg Neurol 1976;5:89-93.

${ }^{29}$ Byfield JE. Ionizing radiation and vincristine: possible neurotoxic synergism. Radiol Clin Biol 1972;41:129-38.

${ }^{30}$ Price RA, Jamieson PA. The central nervous system in childhood leukaemia. Cancer 1975;35:306-18.

${ }^{31}$ Hopewell JW, Wright EA. The nature of latent cerebral irradiation damage and its modification by hypertension. Br J Radiol 1970;43:161-7.

${ }^{32}$ De Reuck J, Vander Eecken $H$. The anatomy of late radiation encephalopathy. Eur Neurol 1975;13:48194.

${ }^{33}$ Sheline GE, Wara WM, Smith V. Therapeutic irradiation and brain injury. Int J Radiat Oncol Biol Phys 1980;6:1215-28.

${ }^{34}$ Martins AN, Johnston JS, Henry JM, Stoffel TJ, DiChiro G. Delayed radiation necrosis of the brain. $J$ Neurosurg 1977;47:336-45.

3s Julow J, Slowik F, Keleman J, Gorácz I. Late postirradiation necrosis of the brain. Acta Neurochir (Wien) 1979;46:135-50.

${ }^{36}$ Sharma U, Tandon PN, Rath GK, et al. Delayed brain necrosis in irradiated adenoid cystic carcinoma of nose-a case report. Indian J Cancer 1980;17:59-63. 